\title{
Similar temperature sensitivity of soil mineral-associated organic carbon regardless of age
}

\section{Karhu, Kristiina}

2019-09

Karhu , K , Hilasvuori , E , Jarvenpaa , M , Arppe , L , Christensen , B T , Fritze , H , Kulmala , L , Oinonen , M , Pitkanen , J-M , Vanhala , P , Heinonsalo , J \& Liski , J 2019 , ' Similar temperature sensitivity of soil mineral-associated organic carbon regardless of age ' , Soil Biology \& Biochemistry , vol. 136 , 107527 . https://doi.org/10.1016/j.soilbio.2019.107527

http://hdl.handle.net/10138/318900

https://doi.org/10.1016/j.soilbio.2019.107527

CC BY-NC-ND

acceptedVersion

Downloaded from Helda, University of Helsinki institutional repository.

This is an electronic reprint of the original article.

This reprint may differ from the original in pagination and typographic detail.

Please cite the original version. 
${ }^{*}$ Highlights (for review)

-Temperature sensitivity of mineral-associated SOM was not related to its age

-Temperature sensitivity of POM fraction was similar or slightly higher than MOM

-Within the POM fraction, old $\mathrm{C}$ was more sensitive to temperature than recent $\mathrm{C}$ 
1 Similar temperature sensitivity of soil mineral-associated organic carbon

2 regardless of age

3

4 Kristiina Karhu ${ }^{\mathrm{a}^{*}}$, Emmi Hilasvuori ${ }^{\mathrm{b}^{*}}$, Marko Järvenpää ${ }^{c \dagger}$, Laura Arppe ${ }^{\mathrm{d}}$, Bent T. Christensen ${ }^{\mathrm{e}}$, Hannu

5 Fritze $^{f}$, Liisa Kulmala ${ }^{\mathrm{a}, \mathrm{g}, \mathrm{h}}$, Markku Oinonen $^{\mathrm{d}}$, Juha-Matti Pitkänen ${ }^{\dagger}$, Pekka Vanhalab $^{\mathrm{b}}$, Jussi Heinonsalog,h,

6 Jari Liski ${ }^{\text {h }}$

$8 \quad$ *Both authors contributed equally to this manuscript

9 a Department of Forest Sciences, University of Helsinki, P.O. Box 27, FI-00014 Helsinki, Finland

$10{ }^{b}$ Finnish Environment Institute, Latokartanonkaari 11, 00790 Helsinki, Finland

$11{ }^{\mathrm{c}}$ Department of Mathematics, Tampere University of Technology, P.O. Box 527, FI-33101 Tampere,

12 Finland

$13{ }^{d}$ Laboratory of Chronology, Finnish Museum of Natural History - LUOMUS, P.O. Box 64, FI-00014

14 Helsinki, Finland

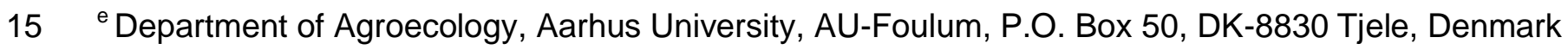

$16{ }^{\mathrm{f}}$ Natural Resources Institute Finland, P.O. Box 18, FI-01301 Vantaa, Finland

$17{ }^{g}$ Institute for Atmospheric and Earth System Research / Forest Sciences , P.O. Box 64, FI-00014

18 University of Helsinki, Finland

$19{ }^{\mathrm{h}}$ Finnish Meteorological Institute, P.O. BOX 503, FI-00101 Helsinki, Finland

$20{ }^{\dagger}$ current address: Department of Computer Science, Aalto University, P.O. Box 15400, FI-00076 Aalto,

$21 \quad$ Finland

22

23

Corresponding author: Kristiina Karhu (kristiina.karhu@helsinki.fi) 
Most of the carbon (C) stored in temperate arable soils is present in organic matter (OM) intimately associated with soil minerals and with slow turnover rates. The sensitivity of mineral-associated OM to changes in temperature is crucial for reliable predictions of the response of soil $\mathrm{C}$ turnover to global warming and the associated flux of carbon dioxide $\left(\mathrm{CO}_{2}\right)$ from the soil to the atmosphere. We studied the temperature sensitivity of $\mathrm{C}$ in $<63 \mu \mathrm{m}$ fractions rich in mineral-associated organic matter (MOM) and of $\mathrm{C}$ in $>63 \mu \mathrm{m}$ fractions rich in particulate organic matter (POM). The fractions were isolated by physical separation of two light-textured arable soils where the C4-plant silage maize had replaced C3-crops 25 years ago. Differences in ${ }^{13} \mathrm{C}$ abundance allowed for calculation of the age of $\mathrm{C}$ in the soil-size fractions (old C, C3-C $>25$ years; recent $\mathrm{C}, \mathrm{C} 4-\mathrm{C}<25$ years). We incubated bulk soils $(<2 \mathrm{~mm})$ and size fractions sequentially at $6,18,26$ and $34^{\circ} \mathrm{C}$ (ramping up and down the temperature scale) and calculated the temperature sensitivity of old and recent $\mathrm{C}$ from ${ }^{12} \mathrm{CO}_{2}$ and ${ }^{13} \mathrm{CO}_{2}$ evolution rates. The temperature sensitivity was similar or slightly higher for POM than for MOM. Within the POM fraction, old C3-C was more sensitive to changes in temperature than recent $\mathrm{C} 4-\mathrm{C}$. For the MOM fraction, the temperature sensitivity was unrelated to the age of C. Quantitative PCR analysis indicated that the proportions of bacteria, archaea and fungi did not change during incubation. Our results suggest that while OM stabilizing mechanisms affect the temperature sensitivity of soil $\mathrm{C}$, temperature sensitivity appears unrelated to the age of mineral-associated OM. abundance, Bayesian statistics

\section{Introduction}

53 Understanding the mechanisms that affect the turnover of organic matter $(\mathrm{OM})$ in soil is crucial in order

54 to predict the response of soil $\mathrm{C}$ storage to changes in climate and land use. The effect of changes in temperature on the decomposition of labile soil $\mathrm{OM}$ is well known, whereas less is known on the temperature effect on $\mathrm{C}$ in soil $\mathrm{OM}$ pools with turnover rates counted in decades and centuries (Trumbore, 2000). The soil OM with slow turnover rates is intimately associated with the soil mineral 
even small changes in turnover rate of stable OM may lead to substantial and long-lasting impacts on the $\mathrm{CO}_{2}$ flux from soil to atmosphere (Trumbore, 2000; Schmidt et al., 2011). This spawns a timely need to link temperature sensitivity to the mechanisms that stabilize or destabilize $C$ in mathematical models that simulate long-term turnover of soil C.

Soil OM persists because either its chemical structure is resistant to enzymes released by decomposers or it has become physically or chemically protected against decomposer activity. The decomposition rate of particulate organic matter (POM) has been linked to its intrinsic chemical complexity (Melillo, 1982; Tuomi et al., 2009), whereas the decomposition rate of stabilized OM relates to its incorporation into organo-mineral complexes and reaction with the extensive surface areas of clay- and silt-sized particles (Christensen, 2001; Kleber et al., 2007).

The decomposition of stable soil OM is often considered to be more sensitive to changes in temperature than that of labile OM (Conant et al., 2008). This concept is based on the Arrhenius equation (Bosatta and Agren, 1999) according to which the temperature sensitivity of chemical reactions increases with increase in activation energy. Stable OM comprises chemically complex molecules for which decomposition reactions require a high activation energy and thus are highly sensitive to temperature. However, OM with long turnover time also includes chemically simple and labile proteins and polysaccharides of microbial origin that have become stabilized in organo-mineral complexes (Kleber et al., 2011). The Arrhenius equation does not necessarily apply when other mechanisms than molecular complexity limit the decomposition process (Davidson et al., 2006). Stabilization by organo-mineral interactions is known to reduce the temperature sensitivity of OM (Gillabel et al., 2010; Moinet et al., 2018), but the temperature sensitivity of OM with different age residing within a given soil size fraction remains unclear (Leifeld and Fuhrer, 2005; Plante et al., 2010; Poeplau et al., 2017).

The effect of OM association with minerals on the temperature sensitivity of recent ( $<25$ years old) C versus older $\mathrm{C}$ has not previously been studied. In this study it was determined by measuring the ${ }^{12} \mathrm{CO}_{2}$ and ${ }^{13} \mathrm{CO}_{2}$ evolved during incubation of $\mathrm{OM}$ fractions that were isolated by physical fractionation of soils sampled in an experiment where C3-plants have been replaced by C4-plants 25 years ago. 
The temperature sensitivity of $\mathrm{C}$ in soil $\mathrm{OM}$ with different mineral association was examined by incubating two particle size fractions $(<63 \mu \mathrm{m}$, mineral- associated $\mathrm{OM}(\mathrm{MOM})$ and $>63 \mu \mathrm{m}$, particulate OM (POM)). The soils were from an experiment where silage maize (a C4-plant) was grown for 25 years on soil previously under C3-plants exclusively. The difference in $\delta^{13} \mathrm{C}$ between plants with the $\mathrm{C} 3$ and the C4 photosynthetic pathway is typically $15 \%$ (O'Leary, 1988). This allowed us to discriminate between old and recent $\mathrm{C}$ (old, $\mathrm{C} 3-\mathrm{C}>25$ years; recent, $\mathrm{C} 4-\mathrm{C}<25$ years) present in a given fraction and between $\mathrm{CO}_{2}$ originating from old and recent soil $\mathrm{C}$. The objectives were to quantify 1 ) the temperature sensitivity of $\mathrm{C}$ residing in POM and MOM, and 2) the sensitivity of differently aged $\mathrm{C}$ associated within each of these size fractions. We hypothesized: 1) that the temperature sensitivity of POM increases with increasing age following Arrhenius equation because chemical recalcitrance controls the decomposition of POM, and 2) that the temperature sensitivity of $C$ in MOM is less affected by age than $C$ in POM because the mineral-association limits the decomposition of MOM. Thus, it follows 3 ) that the overall decomposition of MOM is less sensitive to temperature than POM.

The composition of the soil microbial community may change with OM quality and incubation temperature (Biasi et al., 2005). The balance between fungi, bacteria and archaea during the incubations was determined using quantitative PCR, to reveal if respiration rate and changes in isotopic ratio relate to changes in microbial community (Paterson et al., 2009).

\section{Materials and Methods}

\subsection{Site and sampling}

The study relied on soils sampled in a C3- to C4-vegetation conversion experiment at Askov Experimental Station, Denmark (55.28N, 09.07E). Annual mean temperature and precipitation during 1981-2010 were $8.2^{\circ} \mathrm{C}$ and $1079 \mathrm{~mm}$, respectively. The experiment was established in 1987 when soil $(0-25 \mathrm{~cm})$ was sampled from two agricultural sites. The Askov soil (ASK) has loamy sand texture with $14.1 \%$ clay $(<2 \mu \mathrm{m}), 21.2 \%$ silt $(2-20 \mu \mathrm{m}), 30.6 \%$ fine sand $(20-200 \mu \mathrm{m})$, and $34 \%$ coarse sand $(200-$ $2000 \mu \mathrm{m})$. The Lundgaard soil (LUN) has coarse sand texture with $5.5 \%$ clay, $7.7 \%$ silt, $16 \%$ fine sand and $70.8 \%$ coarse sand. The soils were sieved to $<4 \mathrm{~cm}$ and placed outdoors in large open-ended cylinders $\left(0.76 \mathrm{~m}^{2} ; 50 \mathrm{~cm}\right.$ high) inserted $45 \mathrm{~cm}$ into the ground and resting on undisturbed subsoil. Until 1987, the ASK and LUN soils had been exclusively under C3-crops (mainly cereals). At the start of the 
experiment (1988) both soils had a $\mathrm{C} / \mathrm{N}$ ratio of 13 , and $\mathrm{ASK}$ soil had $\mathrm{pH}$ of 6.4 , and $\mathrm{LUN}$ soil had $\mathrm{pH}$ of 7.6 $\left(\mathrm{H}_{2} \mathrm{O}\right)$. Soil $\mathrm{pH}$ is maintained by occasional addition of $\mathrm{Ca}(\mathrm{OH})_{2}$. Soil $\mathrm{C}$ contents and $\delta{ }^{13} \mathrm{C}$ values are presented in Table 1. Every year since May 1988, the soils have carried the C4-crop silage maize (Zea mays L.). The maize receives NPK mineral fertilizers every spring and is whole-crop harvested for silage in mid-October. Kristiansen et al. (2005) give further details. Soils sampled every two-to-four years since 1988 are archived in air-dry condition. The present study received soil that was sampled in 1988 before the first maize crop (year $=0$ ) and in 2013 after 25 years of maize cultivation (year $=25$ ). The 1988 samples served as reference for the isotopic composition of C3-derived soil C. The soils were sieved to $<2 \mathrm{~mm}$.

\subsection{Soil fractionation and incubation}

The air-dry soil samples from 2013 were divided into four laboratory replicates for physical fractionation, while the amount of soil archived in 1988 did not allow for replication. Samples were soaked overnight in water and fractionated by stirring and wet sieving through a $63-\mu \mathrm{m}$ mesh. Then the $>63 \mu \mathrm{m}$ (POM, including sand) and $<63 \mu \mathrm{m}$ (MOM) size-fractions and bulk soil $(<2 \mathrm{~mm})$ subsamples were dried at room temperature to constant weight. Soil water holding capacity (WHC) was determined separately for each soil fraction before incubation.

Samples of bulk soil, POM and MOM fractions from 2013 were rewetted to $60 \%$ WHC and pre-incubated at $20^{\circ} \mathrm{C}$ for two weeks to remove any labile $\mathrm{C}$ released during the fractionation process (De Nobili et al., 2006). Four replicate samples were incubated in $120 \mathrm{~mL}$ glass bottles with a rubber septum. The amount of sample incubated ranged between 3 and $31 \mathrm{~g}$. The quantity of sample was determined in a preexperiment in order to allow for sufficient $\mathrm{CO}_{2}$ for ${ }^{13} \mathrm{C}$ analysis when using the same incubation times for all fractions. The amounts used for incubation were: $9 \mathrm{~g}$ of ASK bulk soil and $19 \mathrm{~g}$ of LUN bulk soil, $26 \mathrm{~g}$ of $\mathrm{ASK}>63 \mu \mathrm{m}$ fraction and $31 \mathrm{~g}$ of $\mathrm{LUN}>63 \mu \mathrm{m}$ fraction, $9 \mathrm{~g}$ of $\mathrm{ASK}<63 \mu \mathrm{m}$ fraction and $3 \mathrm{~g}$ of $\mathrm{LUN}<$ $63 \mu \mathrm{m}$ fraction. Three replicates were used for measurement of $\mathrm{CO}_{2}$ evolution and one for quantitative PCR (extraction of microbial DNA). After pre-incubation, bottles resided in a water bath for 24 hours to adapt to the first incubation temperature $\left(6^{\circ} \mathrm{C}\right)$. After closing the septum, the bottle headspace was flushed with moist $\mathrm{CO}_{2}$-free air $\left(80 \% \mathrm{~N}_{2}\right.$ and $\left.20 \% \mathrm{O}_{2}\right)$. The soil samples were incubated ramping up and down the temperature steps: $6,18,26$ and $34^{\circ} \mathrm{C}$ (sequential method; Hamdi et al., 2013) to minimize 
potential bias from any change in substrate quality during incubation (Leifeld, 2003). In the sequential method, the $\mathrm{CO}_{2}$-flux at a given temperature, and in our case also the $\delta{ }^{13} \mathrm{C}$ content of the respired $\mathrm{CO}_{2}$,

is the average of the values measured at a given temperature when ramping up and down the temperature scale. The incubation periods were as short as possible to avoid changes in OM quality while ensuring measurable $\mathrm{CO}_{2}$ concentrations. Soil samples equilibrated to the next incubation temperature in a water bath for 24 hours before starting the $\mathrm{CO}_{2}$ collection. Before starting the $\mathrm{CO}_{2}$ collection, the bottle headspace was flushed with $\mathrm{CO}_{2}$-free air. Then the bottles were incubated in the water bath at each temperature level until the $\mathrm{CO}_{2}$ concentration in the headspace reached about 1000 ppm. At that time point we measured the $\mathrm{CO}_{2}$ concentration in the headspace and retrieved gas samples for ${ }^{13} \mathrm{C}$ analysis. Then the bottle was transferred to the next temperature level and the procedure repeated. The incubation times for $\mathrm{CO}_{2}$ collection at each temperature step were: Ramping up the temperature range: $6^{\circ} \mathrm{C}$ : 6 days, $18^{\circ} \mathrm{C}$ : 2 days, $24^{\circ} \mathrm{C}$ : 1 day, $34^{\circ} \mathrm{C}$ : 12 hours, and ramping down the temperature range: $24^{\circ} \mathrm{C}: 1$ day, $18^{\circ} \mathrm{C}: 2$ days, $6{ }^{\circ} \mathrm{C}: 8$ days. The $\mathrm{CO}_{2}$ concentrations were measured using a Hewlett Packard 6890 gas chromatograph equipped with a TC detector and J\&W Scientific Megapore GS-Q column.

\subsection{Isotope analysis}

For isotope analysis, gas samples were retrieved in a He-flushed glass vial (12 ml Exetainer®, Labco Limited, UK) using a syringe. The $\delta^{13} \mathrm{C}$ of the $\mathrm{CO}_{2}$ was determined using a DeltaPlusXL (Thermo Finnigan) continuous flow isotope-ratio mass spectrometer and references NBS-19, NBS-18 and LSVEC to normalize raw isotope data. The analytical precision was $\pm 0.15 \%$ ( $1 \sigma)$.

Subsamples of size fractions and bulk soil were ball-milled for isotope analysis. The C concentrations were measured using $\mathrm{CHN}$-analyser $\left(\mathrm{CHN}-1000\right.$, Leco) and ${ }^{13} \mathrm{C}$ using NC2500 Carlo-Erba analyser

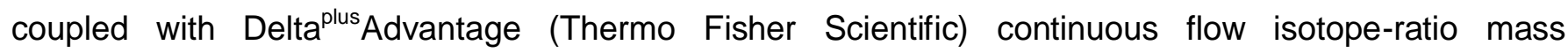
spectrometer. The ${ }^{13} \mathrm{C}$ results are given as $\delta^{13} \mathrm{C} \%$ based on standard V-PDB and reference materials (IAEA-CH3 and IAEA-CH7). The analytical precision was $\pm 0.15 \%(1 \sigma)$. All soil isotope analyses were run in duplicate and results averaged. 
Quantitative PCR (qPCR) was used for examining the proportions of fungi (ITS), bacteria (B16S) and archaea (A16S) in soil at each incubation temperature. Gene copy numbers were determined on the additional set of bottles incubated along with bottles used for $\mathrm{CO}_{2}$-collection. Samples for DNA extraction were taken from the same bottle after incubation at $6,18,26$ and $34^{\circ} \mathrm{C}$, when ramping up the temperature scale. Microbial DNA was extracted from freeze-dried subsamples using the NucleoSpin Soil DNA extraction kit (Macherey-Nagel). Quantitative polymerase chain reaction (qPCR) assays were conducted in thin-walled PCR tubes (Qiagen) on a Rotor-Gene 6000 real time PCR machine (Corbett Life Science). We amplified qPCR products obtained with fungal ITS1F and ITS2 (Gardes and Bruns, 1993; White et al., 1990), bacterial 16S rRNA 1055F and 1392R (Lee et al., 1993; Olsen et al., 1986; Stahl et al., 1988) and archaeal 16S rRNA Arch967f and Arch1060R primer pairs (Amann et al., 1990; Reysenbach and Pace, 1995; Riley-Buckley, 2001). The assays were run with Maxima ${ }^{\mathrm{TM}}$ SYBR Green qPCR Master Mix (2X) (Thermo Scientific) in a $20 \mu$ reaction volume containing $1 \mu$ l template, $0.375 \mu \mathrm{M}$ of each primer, and 1× qPCR master mix. For qPCR conditions see Peltoniemi et al. (2015). Fluorescence was measured at the end of each extension step. The standard curves were constructed with plasmids containing corresponding inserts, taking into account the concentration and molecular mass of the plasmid, including the insert. The samples and standards were run in duplicate. All samples were replicated and absence of PCR inhibition was verified through 1:10 dilution. The copy numbers in samples were calculated based on comparison with threshold cycle values of the standard curve; the numbers are given per gram of soil C. plants, $F_{C 4-\mathrm{C}}$, was estimated as:

$$
F_{C 4-C}=\frac{\delta^{13} C_{t=25}-\delta^{13} C_{t=0}}{\delta^{13} C_{C 4-C}-\delta^{13} C_{t=0}}
$$

where $\delta^{13} C_{t=25}$ is the value of soils retrieved in 2013 and $\delta^{13} C_{t=0}$ is the value of the corresponding samples from 1988. The calculation of $\delta^{13} C_{C 4-C}$ accounts for the small changes in isotopic composition of maize 
biomass recorded over the experimental period (Christensen et al., 2011). This was estimated for year 2013 as follows:

$$
\delta^{13} C_{C 4-C}=-0.043 \text { year }+74.15
$$

The $\mathrm{CO}_{2}$ respiration rates at a given temperature (up and down the temperature range) were averaged. The Gaussian temperature function is as follows:

$$
R(t)=R_{0} e^{a T+b T^{2}}
$$

where $T$ is the temperature $\left({ }^{\circ} \mathrm{C}\right)$ and the parameters are $R_{0}>0, a>0, b<0$ (Tuomi et al., 2008). These were fitted to measurements using Bayesian framework (Gelman et al., 2013). Measurement errors in the Gaussian mode were assumed to be independent and follow a log-normal distribution. This error distribution was a natural choice for exponential model to account heteroscedasticity. The prior information of the parameter $R_{0}$ was modelled with a log-normal distribution with mean 100 and variance $100^{2}$. Uninformative priors were used for parameters $a$ and $b$, that is $p(a, b) \propto 1$. In this way, the following posterior was obtained:

$$
\begin{aligned}
& p\left(\log \left(R_{0}\right), a, b \mid y\right) \propto p\left(\log \left(R_{0}\right)\right) p(a, b) p\left(y \mid \log \left(R_{0}\right), a, b\right) \propto \operatorname{Normal}\left(( V ^ { - 1 } + H ^ { T } H / \sigma ^ { 2 } ) ^ { - 1 } \left(V^{-1} m+\right.\right. \\
& H T y / \sigma 2),(V-1+H T H / \sigma 2)-1
\end{aligned}
$$

where each row in matrix $H$ is $\left[1, T_{i}, T_{i}^{2}\right]$ with measurement temperatures $T_{i}$ and data vector $y$ contains the corresponding $\mathrm{CO}_{2}$ measurements $y_{i}$. The matrix $V$ and vector $m$ relate to prior values. From the above posterior, analytical equations were derived for marginal densities.

The temperature coefficient $Q_{10}$ describes the change in respiration rate when temperature increases by $10^{\circ} \mathrm{C}$ and was calculated from $a$ and $b$ as follows:

$$
Q_{10}(T)=\frac{R(T+10)}{R(T)}=e^{10 a+20 b T+100 b}
$$


resulting in a log-normal posterior distribution for $Q_{10}(T)$.

We analysed the C age using the isotopic composition of soil converted from C3 to C4 vegetation 25 years ago. The soil $\mathrm{C}$ pool was previously observed to be in steady-state equilibrium (Thomsen and Christensen, 2010). This allows a simple calculation of mean residence time (MRT) of $C$ in bulk soil and both POM and MOM fractions using the $\delta^{13} \mathrm{C}$ values according to Amelung et al. (2008):

$$
M R T=-\frac{t}{\ln \left(1-F_{C 4-C}\right)}
$$

where $F_{\mathrm{C} 4-\mathrm{C}}$ is the $\mathrm{C} 4-\mathrm{C}$ fraction of the soil $\mathrm{C}$ pool (Eq. 1) and $t$ is time in years since the vegetation change $(t=25)$. The significance of trends in temperature series was tested with a $t$-test for trend. The calculations for the Eqs. 1-3. and 6 were done in MS Excel. Differences in the qPCR results (logtransformed gene copy numbers) between different SOC fractions were tested with one-way ANOVA combined with Tukey test (IBM SPSS Statistics 22). Test for data normality used the Shapiro-Wilk test, and Levene test was used for testing of homogeneity of variances.

\section{Results}

\subsection{Soil characteristics}

The $<63 \mu \mathrm{m}$ fraction $(\mathrm{MOM})$ had a higher $\mathrm{C}$ concentration and contained more $\mathrm{C}$ than the $>63 \mu \mathrm{m}$ fraction (POM) (Table 1). The MOM represented 67 to $69 \%$ of the total soil C in ASK both in 1988 and 2013. For LUN, MOM accounted for $74 \%$ in 1988 and $57 \%$ in 2013, mainly because of a higher C concentration in POM in 2013. The C concentration in MOM was about $5 \%$ while that in POM ranged

The MOM and POM isolated from LUN soil had very similar $\delta^{13} \mathrm{C}$ values before maize growing started in 1988, whereas for ASK soil MOM was somewhat depleted in ${ }^{13} \mathrm{C}$ compared to POM (Table 1). Maize cultivation increased the $\delta^{13} \mathrm{C}$ values of each soil fraction, and the values of the POM increased most. In 2013, maize-derived C represented $37 \%$ of the C in POM in ASK and $39 \%$ in LUN, while maize-C 
accounted for $14 \%$ of the $C$ in MOM at both sites (see Fig. 4). For LUN as well as ASK soil, the MRT of $\mathrm{C}$ in POM was 50 years and about 170 years for $\mathrm{C}$ in MOM (Table 1).

\subsection{Temperature sensitivity of SOC fractions}

The ASK bulk soil, POM and MOM fractions all showed similar respiration rates during incubation (Fig. 1a). In LUN, the average respiration rate increased from the bulk soil to the MOM and POM. The respiration rates were higher than deducted from the MRTs of the fractions (seen Table 1). For example, the respiration rate measured at $18^{\circ} \mathrm{C}$ equalled $80 \mu \mathrm{g} \mathrm{CO}_{2} \mathrm{~g}^{-1} \mathrm{C}_{\text {hour }}{ }^{-1}$, corresponding to about $0.2 \mathrm{~g} \mathrm{C}$ $\mathrm{g}^{-1} \mathrm{C}$ per year.

The Gaussian equation was used to describe the temperature dependence of the respiration. When fitted to measured respiration from MOM and POM isolated from ASK soil, the $95 \%$ probability distributions of the two parameter values of this equation overlapped only little (Fig. 2a). This indicates a different temperature dependence as illustrated by the $Q_{10}$ value in Figs. $2 c$, e-g. For example, in the temperature range 5 to $15^{\circ} \mathrm{C}$, the most probable $\mathrm{Q}_{10}$ value of the POM equalled 4.8 and that of the MOM 3.6. Because of the Gaussian equation, the $Q_{10}$ values and the temperature sensitivity of the MOM and POM fractions from ASK soil differed for different temperatures. The effect of temperature on the respiration did not differ between size fractions from LUN soil (Fig. 2b, d-g).

The $\delta^{13} \mathrm{C}$ value of respired $\mathrm{CO}_{2}$ was some $4 \%$ higher than that of $\mathrm{C}$ in the corresponding soil fraction

(Fig. 3, Table 1). This indicates that decomposers favoured the younger maize-derived C. Maize-derived C represented $63 \%$ (LUN) and $70 \%$ (ASK) of the C respired from POM, $52 \%$ (ASK) and $60 \%$ (LUN) of the $\mathrm{C}$ respired from bulk soil, and $39 \%$ (ASK and LUN) of the C respired from MOM (Fig. 4). The $\delta^{13} \mathrm{C}$ values did not vary significantly with incubation temperature, except for $\mathrm{C}$ respired from POM isolated from the LUN soil (Fig. 3). Here the $\delta^{13} \mathrm{C}$ decreased with an increasing temperature indicating that an increasing proportion of the older C3-C was respired at higher temperatures.

\subsection{Microbial community composition measured by quantitative PCR}

287 The ITS, B16S and A16S copy numbers did not change systematically with incubation temperature. In 288 the ASK soil, the POM fraction had lower ITS, A16S and B16S copy numbers per mg soil C than bulk soil and MOM, but these differences were not statistically significant at all temperatures (Fig. 5). In the 
LUN soil, the MOM fraction had higher ITS and B16S gene copy numbers compared to bulk soil and POM fraction (Fig. 5).

\section{Discussion}

293 We studied the temperature dependence of $C$ in bulk soil and their particle size fractions from two 294 differently textured arable soils converted from C3-plants to C4-plants 25 years ago. The $>63 \mu \mathrm{m}$ fraction 295 with a MRT of decades is dominated by particulate organic matter (POM), whereas the $<63 \mu \mathrm{m}$ fraction 296 is dominated by OM intimately associated with soil minerals (MOM) and with a MRT of more than a 297 century. Our estimates of old C3-derived $C$ and recent $C 4$-derived $C$ depend on $\delta^{13} C_{y=0}$, determined for 298 the soils before maize cultivation was initiated in 1988. Accounting for the annual increase in $\delta^{13} \mathrm{C}_{\mathrm{y}=0}$ of $2990.0083 \%$ (Christensen et al., 2011) changed the percentages of C3-C and C4-C in soil particle size 300 fractions by only $1 \%$. Menichetti et al. (2015) showed that in experiments lasting for more than three to 301 four decades, isotopic fractionation could lead to larger changes in soil $\delta^{13} \mathrm{C}$.

Our study relied on air-dried and sieved soil samples and a soil fractionation procedure that eliminates soil structure. The potential effect of the rewetting on the observed temperature sensitivity of the soil OM was minimized by pre-incubating samples for two weeks. The pre-incubation showed a flush of $\mathrm{CO}_{2}$ for bulk soil as well as POM from the LUN soil (Fig. S1), suggesting that this flush of $\mathrm{CO}_{2}$ was not only due to fractionation procedure. Based on the decreasing respiration rates during the pre-incubation it was estimated that the $\mathrm{C}$ released from bulk soil accounts for less than $30 \%$ of $\mathrm{C}$ in the $>63 \mu \mathrm{m}$ fraction and more than $70 \%$ of $\mathrm{C}$ in the $<63 \mu \mathrm{m}$ fraction. If the respiration rate of the $>63 \mu \mathrm{m}$ fraction did not change due to fractionation, then the unexplained increase in the respiration rate of $<63 \mu \mathrm{m}$ fraction after fractionation corresponds to $11 \%$ and $42 \%$ of the total respiration in ASK and LUN, respectively. Thus, part of the respiration from POM as well as MOM may originate from $\mathrm{C}$ released during re-wetting and

313 fractionation. For both soils, however, old C-3 derived C made up a larger proportion of the C respired 314 from MOM than from POM. For POM, a larger part of the soil $\mathrm{C}$ and respired $\mathrm{C}$ originated from recent $\mathrm{C}$ 3154 derived C (Fig. 4). This suggests that we did manage to separate two soil fractions with OM of different 316 age, allowing us to compare the temperature sensitivity of soil $\mathrm{C}$ older and younger than 25 years. 
318 We estimate that on average $0.9 \%$ of the soil $\mathrm{C}$ was lost during the incubation. With this incubation set319 up, it was also possible to observe if the isotopic signature changed to the same direction when moving up and down of the temperature scale (e.g. for POM in LUN, the $\delta^{13} \mathrm{C}$ value exhibits slopes of -0.046 and -0.060 with increasing temperature when measured up and down the temperature scale). Therefore, we do not consider changes in substrate quality during the incubation to have affected our results.

\subsection{Temperature sensitivity and age of $\mathrm{C}$}

In the LUN soil, the relative contribution of C3-derived $C$ to respiration from POM increased with temperature (Fig. 3), reflecting a higher temperature sensitivity of the old C3-C than the recent maizederived C4-C. This is ascribed to a chemically more complex structure of the part of POM that has survived for $>25$ years. The surviving old POM demands higher activation energy and thus shows higher temperature sensitivity.

The high temperature sensitivity of old $\mathrm{C}$ in the POM fraction supports our first hypothesis that $\mathrm{C}$ release from this fraction follows Arrhenius kinetics. We hypothesised that mineralisation of $C$ in this fraction reflects the intrinsic temperature sensitivity of $\mathrm{C}$ in POM as this fraction is freely available to microbes. However, this effect of age was less pronounced in ASK loamy sand, and the trend was not statistically significant. This may be due to less complete soil dispersion in the more clayey ASK soil. Even though the fractionation procedure aimed at breaking all soil aggregates, some microaggregates $(63-250 \mu \mathrm{m})$ in the ASK soil may have survived dispersion. This may explain why the ASK size fractions and bulk soil had rather similar respiration rates. For the coarser LUN soil with a more complete soil dispersion, POM showed higher respiration rate. There was slightly more old C3-C respired from the POM fraction of the LUN soil compared with that of the ASK soil, even though the proportions of C3-C and C4-C in POM were almost identical for both soils. This supports the previous notion that physical protection of $C$ within

There was no change with temperature in the isotopic signal of $\mathrm{CO}_{2}$ from the $\mathrm{MOM}$ fraction, suggesting 344 that mineral-associated recent $\mathrm{C} 4-\mathrm{C}$ and old $\mathrm{C} 3-\mathrm{C}$ in MOM exhibit similar temperature sensitivity. This supports our second hypothesis stating that temperature sensitivity of MOM is less affected by age than that of POM. Our results indicate that the most temperature sensitive OM pool in soil is the free, but chemically recalcitrant $\mathrm{C}$ with intermediate turnover time, aligning with recent studies, which have also 
found that $C$ fractions with decadal-scale turnover times show the highest temperature sensitivity (Gillabel et al., 2010; Hopkins et al., 2012).

\subsection{Temperature sensitivity of soil $\mathrm{C}$ fractions}

Our third hypothesis stated that organo-mineral (MOM) association of $\mathrm{C}$ reduces its intrinsic temperature sensitivity compared to $\mathrm{C}$ in POM. This hypothesis was only partially supported by the lower temperature sensitivity of MOM and higher sensitivity of POM in ASK soil (Fig. 2a) as illustrated by different $Q_{10}$ values, especially in the temperature range of $5-15^{\circ} \mathrm{C}$ (Fig. 2e). This is in line with previous studies showing that stabilization of $\mathrm{C}$ in organo-mineral complexes reduces its temperature sensitivity (Gillabel et al., 2010; Moinet et al., 2018). However, differences in $Q_{10}$ s of the incubated size fractions were less clear at higher temperatures and not statistically significant for LUN soil. We speculate that the stabilising effect of organo-mineral interaction was stronger in MOM from the finer textured ASK soil, whereby stabilisation with minerals reduced the $Q_{10}$ more compared to the $Q_{10}$ of $C$ in POM, which was similar for both soils.

Studies using incubations of physically or chemically isolated fractions to study their temperature sensitivity are scarce and results are partly contradictory. Plante et al. (2010) found the $Q_{10}$ to increase in the order: hydrolysis residue $<\mathrm{POM}<$ whole soil. In their study, POM was fractionated with wet sieving size-separation method comparable to our study, whereas $Q_{10}$ was determined from long-term (126days) parallel incubations. This could have decreased the $Q_{10}$ of labile POM fraction more relative to bulk soil $Q_{10}$ values. Contrary to Plante et al. (2010), in our study there were no clear differences between the $Q_{10}$ values of POM and bulk soil. Benbi et al. (2014) found higher temperature sensitivity for POM compared to MOM, which aligns with our results from the ASK soil. Their study relied on a sizefractionation procedure similar to that of our study, but divided POM into two size classes (53-250 $\mu \mathrm{m}$ and 250-2000 $\mu \mathrm{m}$ ). Ding et al. (2014) reached opposite results, and found that the $Q_{10}$ for the different size-fractions increased in the order: sand<silt<clay. In their study, however, soil dispersion by ultrasonication and the crushing of the size-fractions after drying prior to incubation could have increased the availability of mineral associated $\mathrm{OM}$. Flocculation of clay with $\mathrm{CaCl}_{2}$ could have also affected $\mathrm{C}$ availability from that fraction. Leifeld and Fuhrer (2005) found little difference between size fractions $(<63$ $\mu \mathrm{m}$ and $>63 \mu \mathrm{m}$ ) whereas $\mathrm{C}$ in residues from acid hydrolysis of finer sized soil fractions showed a high sensitivity to temperature. The residue obtained after acid hydrolysis is considered less suitable for 
studying stable $\mathrm{C}$ in incubations studies. The isolated soil $\mathrm{OM}$ fractions are impacted by chemical changes that may make mineral associated C either more available (Leifeld and Fuhrer, 2005) or less available due to cation bridging with $\mathrm{Ca}^{2+}$ added to neutralise $\mathrm{pH}$ after hydrolysis (Plante et al., 2010). Our fractionation procedure avoided these pitfalls. However, laboratory incubations with optimal conditions for microbial decomposition always provide shorter turnover time estimates than methods based on changes in the abundance of ${ }^{13} \mathrm{C}$ after C3- to C4-vegetation change (Feng et al., 2016). This was also true in our study. Although decomposition rates of MOM in incubation studies may not refer directly to field conditions, they are still valid when comparing the temperature sensitivity of older versus younger $\mathrm{C}$ in a given fraction.

\subsection{Microbial balance}

The composition of the microbial community may affect mineralization rates and the isotopic composition of respired $\mathrm{CO}_{2}$ (Paterson et al., 2009). We did not directly analyse the microbial community, but estimated the balance of the community targeting the three domains fungi, bacteria and archaea of the microbial community by qPCR. No significant changes in the balance were observed with temperature although the relative abundance of archaeal 16S rRNA copy numbers tended to increase with temperature. Archaea are the least abundant microbial group in soil (Tamez-Hidalgo et al., 2016), and their functional importance is less understood than that of bacteria and fungi. The small changes in this microbial group are unlikely to explain observed changes in $\mathrm{CO}_{2}$ production or isotope signatures of respired $\mathrm{CO}_{2}$. The rather similar balance between the three domains in soil-size fractions and bulk soils suggests that trends in isotopic composition of respired $\mathrm{CO}_{2}$ were not derived from differences in the composition of the microbial community. The qPCR analysis showed higher gene copy numbers in the MOM than in the POM fraction isolated from LUN soil. Most of the decomposer community live attached to the surfaces of clay and silt particles (Mills, 2003), whereby these particles may become enriched in gene copies. Because qPCR records genes associated with live as well as dead microbial biomass, a higher gene copy number in the MOM fraction may indicate a larger contribution of microbial necromass to the stabilised C in this fraction (Liang et al., 2017).

\section{Conclusions}

The temperature sensitivity of $\mathrm{C}$ in the $<63 \mu \mathrm{m}$ particle size fraction (MOM), dominated by mineral associated $C$, was smaller or similar to the sensitivity of $C$ in the $>63 \mu \mathrm{m}$ size fraction (POM). The 
temperature sensitivity of respiration increased with age of $C$ in the POM fraction while the sensitivity

408

409

410 was unaffected by age of $\mathrm{C}$ in the MOM fraction where $\mathrm{OM}$ is stabilised by association with minerals. No evidence was found for highly temperature sensitive $\mathrm{C}$ being a significant component of the MOM fraction. Our results imply similar temperature sensitivity of older and younger $\mathrm{C}$, when residing in organo-mineral associations. This aligns with recent evidence suggesting that the most temperature sensitive $\mathrm{C}$ is in soil $\mathrm{OM}$ pools cycling on intermediate time scales. Our results suggest that the temperature sensitivity of most of the $C$ residing in arable topsoils relates to the mechanisms that stabilize $\mathrm{C}$ in soil rather than to the age of the OM stabilized in organo-mineral complexes.

\section{Acknowledgements}

This work is part of project DECORATE (138359) funded by The Academy of Finland, and Carbon Action project funded by The Finnish Innovation Fund Sitra. We thank Sonia Sanz Muñoz for qPCR analysis at LUKE and Igor Shevchuk for isotope analysis at the Laboratory of Chronology and Joonas Uusitalo for assistance. The Danish contribution was financially supported by the Ministry of Environment and Agriculture.

\section{Literature}

Amann, R.I., Krumholz, L., Stahl, D.A., 1990. Fluorescent-oligonucleotide probing of whole cells for determinative, phylogenetic, and environmental-studies in microbiology. Journal of Bacteriology 172 , 762-770.

Amelung, W., Brodowski, S., Sandhage-Hofmann, A., Bol, R., 2008. Combining biomarker with stable isotope analyses for assessing the transformation and turnover of soil organic matter. Advances in Agronomy 100, 155-250.

Balesdent, J., Mariotti, A., 1996. Measurement of soil organic matter turnover using ${ }^{13} \mathrm{C}$ natural abundances. In: Boutton, T.W., Yamasaki, S.I. (Eds.), Mass Spectrometry of Soils. Marcel Dekker Inc., New York, pp. 83-111. 
Biasi, C., Rusalimova, O., Meyer, H., Kaiser, C, Wanek, W., Barsukov, P, Junger, H., Richer, A. 2005.

434 Temperature-dependent shift from labile to recalcitrant carbon sources of arctic heterotrophs. Rapid

435 Communications in Mass Spectrometry 19:1401-1408.

436 Benbi, D.K., Boparai, A.K., Brar, K., 2014. Decomposition of particulate organic matter is more sensitive 437 to temperature than the mineral associated organic matter. Soil Biology \& Biochemistry 70, 183-192.

438 Bosatta, E., Agren, G.I., 1999. Soil organic matter quality interpreted thermodynamically. Soil Biology \& 439 Biochemistry 31, 1889-1891.

440 Christensen, B.T., 2001. Physical fractionation of soil and structural and functional complexity in organic 441 matter turnover. European Journal of Soil Science 52, 345-353.

442 Christensen, B.T., Olesen, J.E., Hansen, E.M., Thomsen, I.K., 2011. Annual variation in delta(13)C 443 values of maize and wheat: Effect on estimates of decadal scale soil carbon turnover. Soil Biology \& 444 Biochemistry 43, 1961-1967.

445 Conant, R.T., Drijber, R.A., Haddix, M.L., Parton, W.J., Paul, E.A., Plante, A.F., Six, J., Steinweg, J.M., 446 2008. Sensitivity of organic matter decomposition to warming varies with its quality. Global Change 447 Biology 14, 868-877.

448 Davidson, E.A., Janssens, I.A., Luo, Y.Q., 2006. On the variability of respiration in terrestrial 449 ecosystems: moving beyond Q(10). Global Change Biology 12, 154-164.

450 De Nobili, M., Contin, M., Brookes, P.C., 2006. Microbial biomass dynamics in recently air-dried and 451 rewetted soils compared to others stored air-dry for up to 103 years. Soil Biology \& Biochemistry 38 , $452 \quad 2871-2881$.

453 Ding, F., Huang, Y., Sun, W.J., Jiang, G.F., Chen, Y., 2014. Decomposition of Organic Carbon in Fine 454 Soil Particles Is Likely More Sensitive to Warming than in Coarse Particles: An Incubation Study with 455 Temperate Grassland and Forest Soils in Northern China. Plos One 9, e95348.

456 Feng, W., Shi, Z., Jiang, J., Xia, J., Liang, J., Zhou, J., Luo, Y., 2016. Methodological uncertainty in 457 estimating carbon turnover times of soil fractions. Soil Biology \& Biochemistry 100, 118-124.

458 Gardes, M., Bruns, T.D., 1993. ITS primers with enhanced specificity for basidiomycetes - application to 459 the identification of mycorrhizae and rusts. Molecular Ecology 2, 113-118.

460 Gelman, A., Carlin, J.B., Stern, H.S., Dunson, D.B., Vehtari, A., Rubin, D.B., 2013. Bayesian Data 461 Analysis, Third Edition. Taylor \& Francis. Boca Raton. 
Gillabel, J., Cebrian-Lopez, B., Six, J., Merckx, R., 2010. Experimental evidence for the attenuating effect of SOM protection on temperature sensitivity of SOM decomposition. Global Change Biology 16, 2789-2798.

Hamdi, S., Moyano, F., Sall, S., Bernoux, M., Chevallier, T., 2013. Synthesis analysis of the temperature sensitivity of soil respiration from laboratory studies in relation to incubation methods and soil conditions. Soil Biology \& Biochemistry 58, 115-126.

Hopkins, F.M., Torn, M.S., Trumbore, S.E., 2012. Warming accelerates decomposition of decades-old carbon in forest soils. Proceedings of the National Academy of Sciences of the United States of America 109, E1753-E1761.

Kleber, M., Sollins, P., Sutton, R., 2007. A conceptual model of organo-mineral interactions in soils: selfassembly of organic molecular fragments into zonal structures on mineral surfaces. Biogeochemistry 85 , 9-24.

Kleber, M., Nico, P.S, Plante, A., Filley, T., Kramer, M., Swanston, C., Sollins, P., 2011. Old and stable soil organic matter is not necessarily chemically recalcitrant: implications for modelling concepts and temperature sensitivity. Global Change Biology 17, 1097-1107, Kristiansen, S.M., Hansen, E.M., Jensen, L.S., Christensen, B.T., 2005. Natural C-13 abundance and carbon storage in Danish soils under continuous silage maize. European Journal of Agronomy 22, 107117.

Lee, S.H., Malone, C., Kemp, P.F., 1993. Use of multiple 16S ribosomal-RNA-targeted fluorescentprobes to increase signal strength and measure cellular RNA from natural planktonic bacteria. Marine Ecology Progress Series 101, 193-201.

Leifeld, J., 2003. Comments on "Recalcitrant soil organic materials mineralize more efficiently at higher temperatures" by R. Bol, T. Bolger, R. Cully, and D. Little; J. Plant Nutr. Soil Sci 166, 300-307 (2003). Journal of Plant Nutrition and Soil Science 166, 777-778.

Leifeld, J., Fuhrer, J., 2005. The temperature response of CO2 production from bulk soils and soil fractions is related to soil organic matter quality. Biogeochemistry 75, 433-453.

Liang, C., Schimel, J.P., Jastrow, J.D. 2017. The importance of anabolism in microbial carbon over soil carbon storage. Nature Microbiology 2, 17105.

Melillo, J.M., Aber, J.D., Muratore, J.F., 1982. Nitrogen and lignin control of hardwood leaf litter decomposition dynamics. Ecology 63, 621-626. 
Menichetti, L., Houot, S., van Oort, F., Katterer, T., Christensen, B.T., Chenu, C., Barre, P., Vasilyeva,

493 N.A., Ekblad, A., 2015. Increase in soil stable carbon isotope ratio relates to loss of organic carbon:

494 results from five long-term bare fallow experiments. Oecologia 177, 811-821.

495 Mills, A.L., 2003. Keeping in touch: microbial life on soil particle surfaces. Advances in Agronomy 78, 149643.

497 Moinet, G.Y.K., Hunt, J.E., Kirschbaum, M.U.F., Morcom, C.P., Midwood, A.J., Millard, P., 2018. The 498 temperature sensitivity of soil organic matter decomposition is constrained by microbial access to 499 substrates. Soil Biology \& Biochemistry 116, 333-339.

500 O'Leary, M.H., 1988. Carbon isotopes in photosynthesis. Bioscience 38, 328-336.

501 Olsen, G.J., Lane, D.J., Giovannoni, S.J., Pace, N.R., Stahl, D.A., 1986. Microbial ecology and evolution 502 - a ribosomal-RNA approach. Annual Review of Microbiology 40, 337-365.

503 Paterson, E., Midwood, A.J., Millard, P., 2009. Through the eye of the needle: a review of isotope 504 approaches to quantify microbial processes mediating soil carbon balance. New Phytologist 184, 19-33. 505 Peltoniemi, K., Laiho, R., Juottonen, H., Kiikkila, O., Makiranta, P., Minkkinen, K., Pennanen, T., Penttila, 506 T., Sarjala, T., Tuittila, E.-S., Tuomivirta, T., Fritze, H., 2015. Microbial ecology in a future climate: effects 507 of temperature and moisture on microbial communities of two boreal fens. FEMS Microbiology Ecology 508 91, fiv062, https://doi.org/10.1093/femsec/fiv062.

509 Plante, A.F., Conant, R.T., Carlson, J., Greenwood, R., Shulman, J.M., Haddix, M.L., Paul, E.A., 2010. 510 Decomposition temperature sensitivity of isolated soil organic matter fractions. Soil Biology \& 511 Biochemistry 42, 1991-1996.

512 Poeplau, C., Kätterer, T., Leblans, N.I.W., Sigurdsson, B., 2017. Sensitivity of soil carbon fractions and 513 their specific stabilization mechanisms to extreme soil warming in a subarctic grassland. Global Change 514 Biology 23, 1316-1327.

515 Reysenbach, A.-L., Pace, N.R., 1995. Reliable amplification of hyperthermophilic Archaeal 16S rRNA 516 genes by the polymerase chain reaction, In: Robb, F.T., Place, A.R., Sowers, K.R., Schreier, A.R., 517 DasSarna, S., Fleischman, E.M. (Eds.), Archaea: A Laboratory Manual. Cold Spring Harbor Laboratory 518 Press, New York, USA, pp. 101-105.

519 Riley-Buckley, S.M., 2001. Microbial communities in pristine and tetrachlorine-contaminated aquifer 520 sediments. Ph.D. Thesis. Michigan State University, Michigan, USA. 
Schmidt, M.W.I., Torn, M.S., Abiven, S., Dittmar, T., Guggenberger, G., Janssens, I.A., Kleber, M., Kögel-Knabner, I., Lehmann, J., Manning, D.A.C, Nannipieri, P, Rasse, D.P., Weiner, S., Trumbore,

S.E., 2011. Persistence of soil organic matter as an ecosystem property. Nature 478, 50-56.

524 Stahl, D.A., Flesher, B., Mansfield, H.R., Montgomery, L., 1988. Use of phylogenetically based 525 hybridization probes for studies of ruminal microbial ecology. Applied and Environmental Microbiology $54,1079-1084$.

Tamez-Hidalgo, P., Christensen, B.T., Lever, M.A., Elsgaard, L., Lomstein, B.Aa., 2016. Endospores, prokaryotes, and microbial indicators in arable soils from three long-term experiments. Biology and 529 Fertility of Soils 52, 101-112.

530 Thomsen, I.K., Christensen, B.T., 2010. Carbon sequestration in soils with annual inputs of maize 531 biomass and maize-derived animal manure: Evidence from 13C abundance. Soil Biology \& Biochemistry 42, 1643-1646.

Trumbore, S., 2000. Age of soil organic matter and soil respiration: Radiocarbon constraints on belowground C dynamics. Ecological Applications 10, 399-411.

535 Tuomi, M., Vanhala, P., Karhu, K., Fritze, H., Liski, J., 2008. Heterotrophic soil respiration - Comparison 536 of different models describing its temperature dependence. Ecological Modelling 211, 182-190.

537 Tuomi, M., Thum, T., Järvinen, H., Fronzek, S., Berg, B., Harmon, M., Trofymow, J.A., Sevanto, S. \& 538 Liski, J. 2009. Leaf litter decomposition - Estimates of global variability based on Yasso07 model.

539 Ecological Modelling 220:3362-3371. doi:10.1016/i.ecolmodel.2009.05.016

540 White, T.J., Bruns, T., Lee, S., Taylor, J., 1990. Analysis of phylogenetic relationships by amplification 541 and direct sequencing of ribosomal RNA genes, In: Innis, M.A., Gelfand, D.H., Sninsky, J.J., White, T.J. 542 (Eds.), PCR Protocols: a Guide to Methods and Applications Academic Press, New York, USA, pp. 315543322.

\section{Figure captions}

545 Figure 1. Measured respiration rates at different temperatures and the modelled Gaussian temperature curve for soil particle size fractions and bulk soil: 1 a) ASK and 1 b) LUN.

548 Figure 2. 95\% probability contours of parameter values $a$ and $b$ in the Gaussian model for the bulk soil and particle size fractions in ASK (a) and in LUN (b), $Q_{10}$ as a function of temperature in ASK (c) and in 
550 LUN (d). Dashed lines represents 95\% credible intervals (Bayesian confidence intervals). Posterior 551 distributions of $\mathrm{Q}_{10}$ calculated for temperature range of $5-15^{\circ} \mathrm{C}(\mathrm{e}), 15-25^{\circ} \mathrm{C}$ (f) and $25-35^{\circ} \mathrm{C}(\mathrm{g})$.

553 Figure 3. Mean \pm standard deviation $(\mathrm{N}=6)$ of isotopic composition of $\mathrm{CO}_{2}$ respired from the bulk soils 554 and soil size fractions at different temperatures in ASK (a) and in LUN (b). Lines represent linear 555 regressions fitted to the means: a) ASK: MOM ( $\left.y=0.03 x-22.44, R^{2}=0.70, p=0.16\right), P O M(y=-0.03 x-$ $\left.55616.59, R^{2}=0.63, p=0.21\right)$, Bulk soil $\left.\left(y=0.01 x-19.94, R^{2}=0.08, p=0.72\right) b\right)$ LUN: MOM $(y=-0.00 x-21.24$, $\left.557 \quad R^{2}=0.01, p=0.89\right)$, POM $\left(y=-0.05 x-16.80, R^{2}=0.92, p=0.04\right)$, bulk soil $\left(y=-0.05 x-17.49, R^{2}=0.68\right.$, $558 \mathrm{p}=0.18)$. The trend in POM fraction $(>63 \mu \mathrm{m})$ in LUN is statistically significant.

560 Figure 4. The proportions of $\mathrm{C} 4-\mathrm{C}$ and $\mathrm{C} 3-\mathrm{C}$ in soil and in respired $\mathrm{CO}_{2}$ calculated from their isotopic 561 composition in ASK (a) and LUN (b). The $\delta^{13} \mathrm{C}$ values for $\mathrm{CO}_{2}$ are averages four replicates and 4 562 temperatures measured twice.

564 Figure 5. Mean \pm standard deviation of the gene copy numbers/ mg soil C for ITS gene in a) ASK and b) 565 LUN, for B16S in c) ASK and d) LUN, and A16S in e) ASK and f) LUN. The Anova and Tukey's test for 566 differences in gene copy numbers between different SOC fractions (bulk, MOM $<63 \mu \mathrm{m}$ and POM $<63$ $567 \mu \mathrm{m})$ were tested separately in each temperature. Different letters indicate statistically significant 568 differences between fractions. The figure presents non-transformed data, but the $y$-axis in the figure is in 569 log-scale. For the statistical analysis log-transformed data was used. 
572 Table 1. Mean \pm standard deviation of $C$ contents, mass proportions and isotopic composition of ASK

573 and LUN bulk soils, POM and MOM fractions in 1988 and 2013 as well as the mean residence time

574 (MRT) of $\mathrm{C}$. In 2013, $\mathrm{N}=2$ for $\delta^{13} \mathrm{C}$ except for the POM fraction where $\mathrm{N}=8$.

\begin{tabular}{r|ccc|cccc} 
& \multicolumn{5}{|c|}{$1988(\mathrm{t}=0)$} & \multicolumn{4}{c}{$2013(\mathrm{t}=25)$} \\
& $\mathrm{C}(\%)$ & Mass (\%) & $\delta^{13} \mathrm{C}(\%)$ & $\mathrm{C}(\%)$ & Mass $(\%)$ & $\delta^{13} \mathrm{C}(\%)$ & MRT years \\
\hline ASK & 2 & 1 & 4 & 2 & 4 & $2 / 8$ & \\
Bulk soil & $2.5 \pm 0.1$ & 100 & $-27.9 \pm 0.2$ & $2.4 \pm 0.1$ & 100 & $-24.5 \pm 0$ & $100 \pm 4$ \\
MOM & $5.4 \pm 0.3$ & 33 & $-28.2 \pm 0.1$ & $5.7 \pm 0.3$ & $32 \pm 3.9$ & $-26.1 \pm 0.1$ & $170 \pm 8$ \\
POM & $1.3 \pm 0.3$ & 67 & $-27.4 \pm 0.4$ & $1.2 \pm 0.1$ & $68 \pm 3.9$ & $-22.1 \pm 0.8$ & $54 \pm 9$ \\
LUN & & & & & & & \\
Bulk soil & $1 \pm 0.1$ & 100 & $-26.9 \pm 0$ & $0.9 \pm 0$ & 100 & $-22.6 \pm 0.3$ & $71 \pm 7$ \\
MOM & $4.8 \pm 0.1$ & 15 & $-26.7 \pm 0.2$ & $4.9 \pm 0.1$ & $12 \pm 1.7$ & $-24.8 \pm 0.2$ & $170 \pm 15$ \\
POM & $0.3 \pm 0.2$ & 85 & $-26.7 \pm 0.5$ & $0.5 \pm 0.2$ & $88 \pm 1.7$ & $-21.4 \pm 1$ & $51 \pm 12$ \\
\hline
\end{tabular}




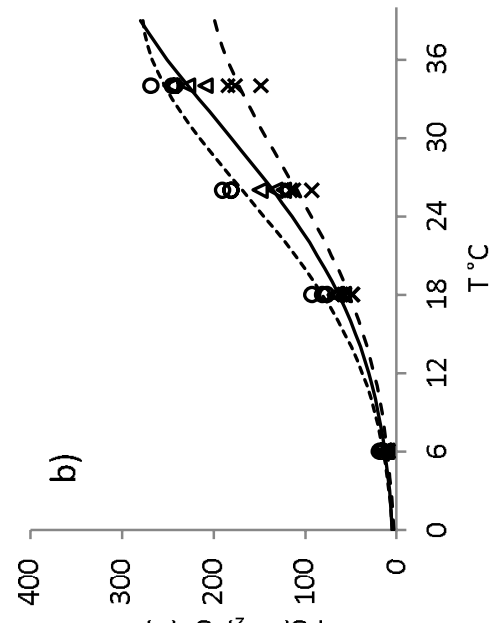

$\tau-4(0)^{t}-8\left({ }^{2} 05\right) 84$

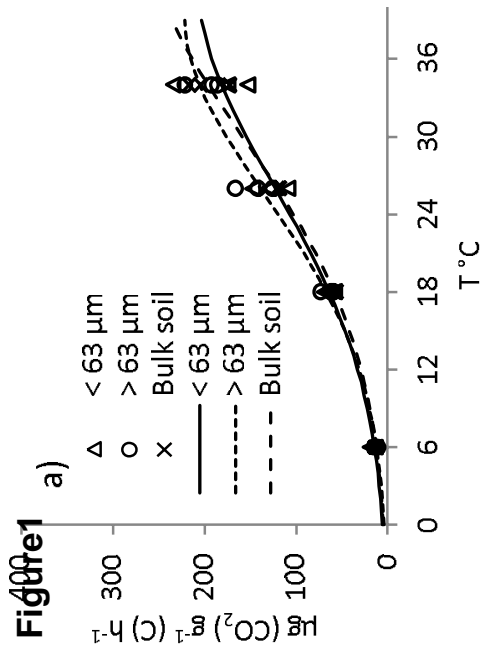




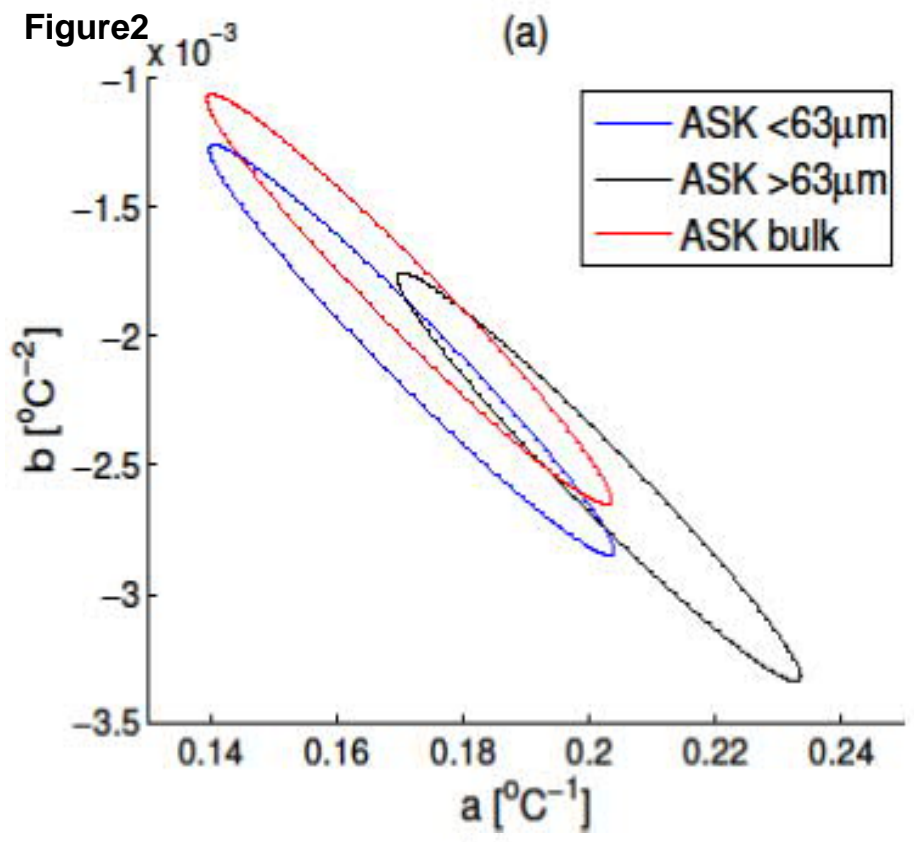

(c)

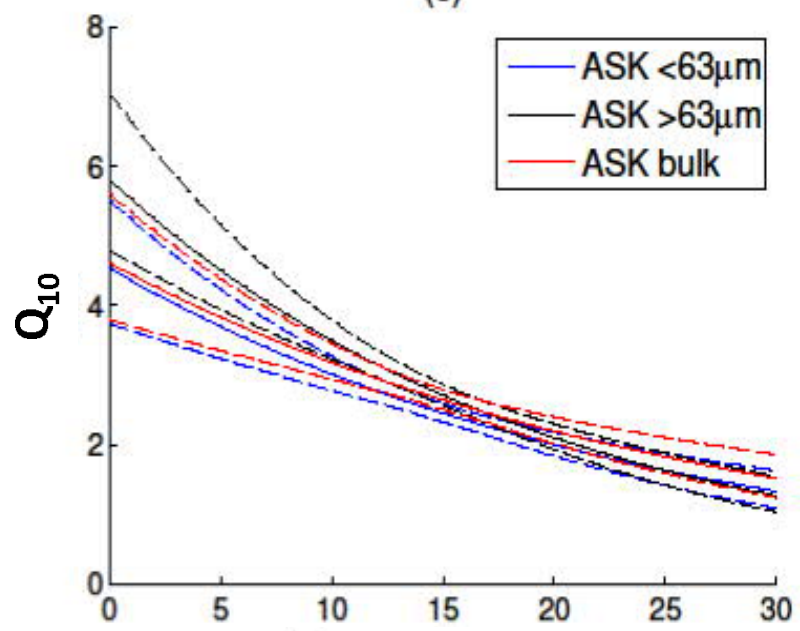

(e)
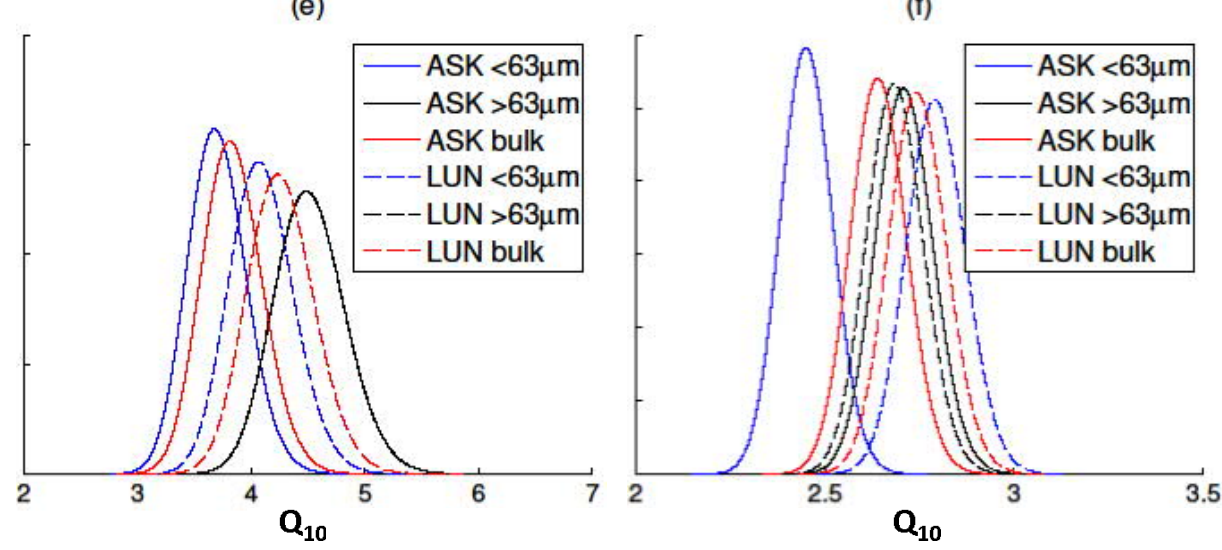

(b)

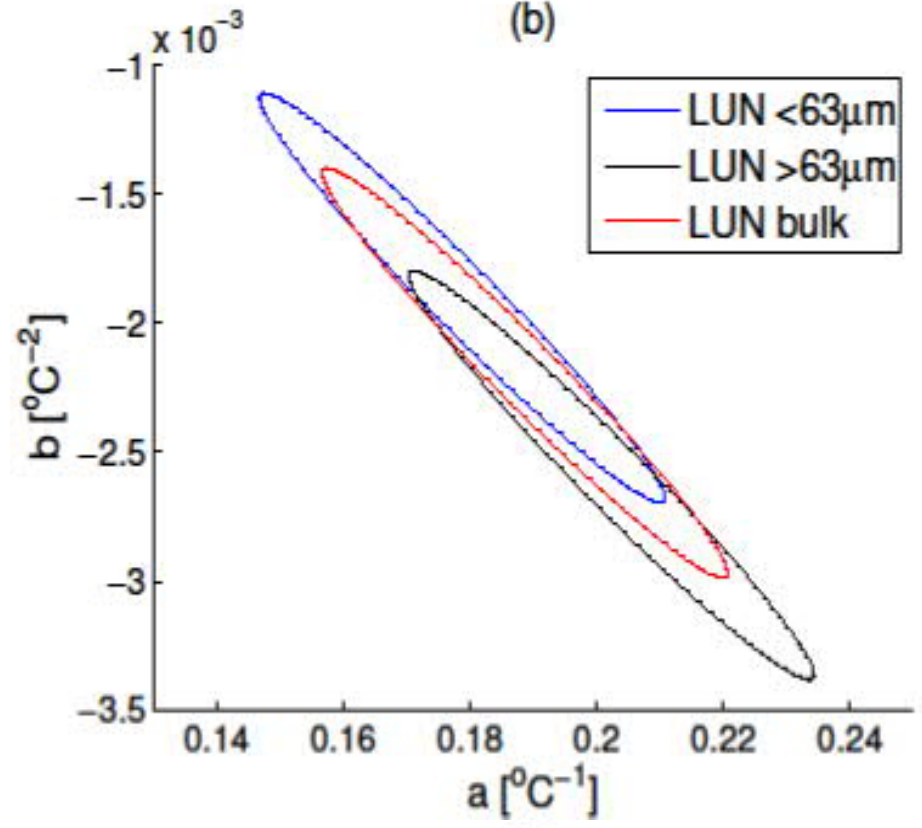

(d)
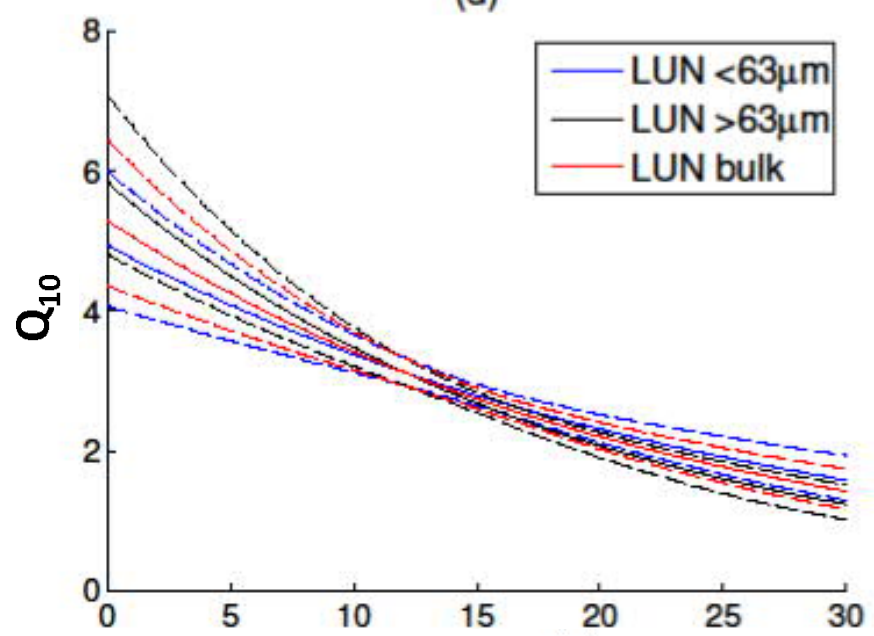

(g)

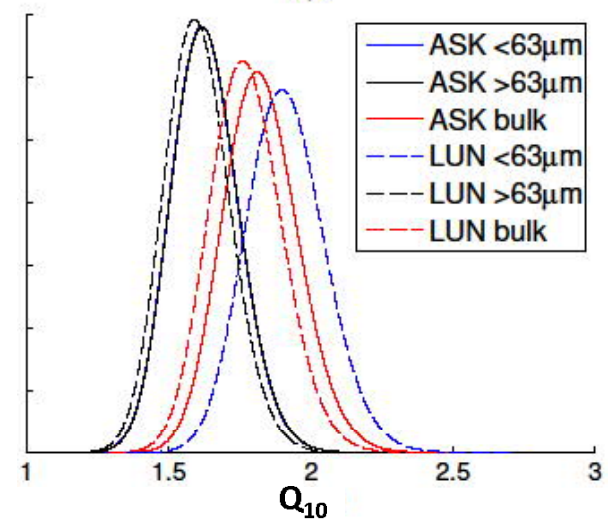



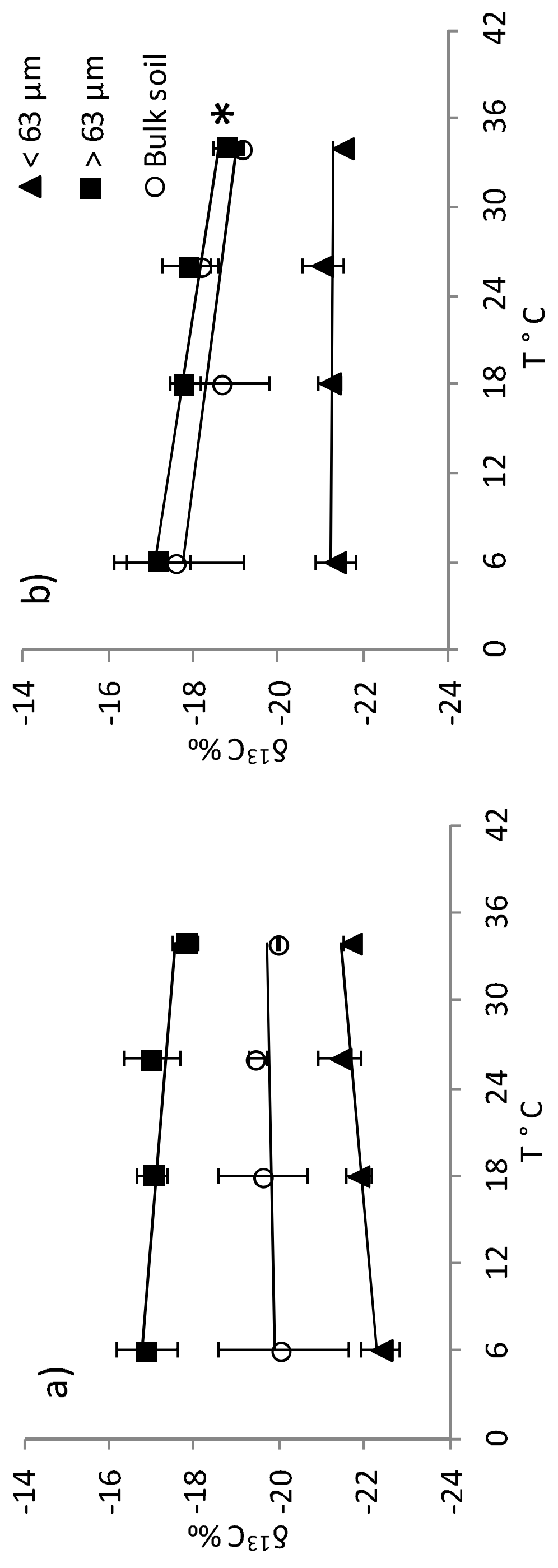


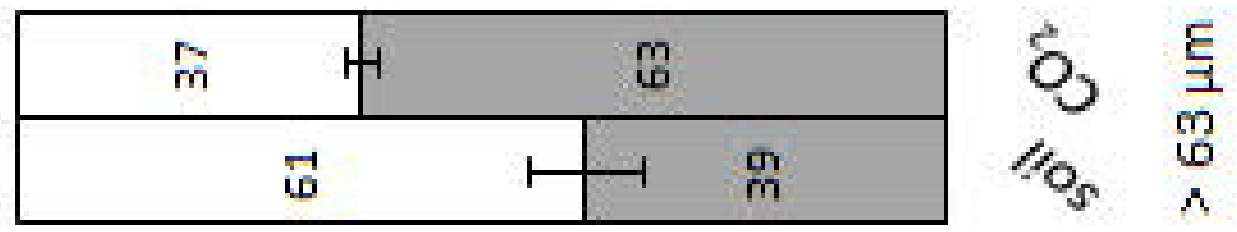
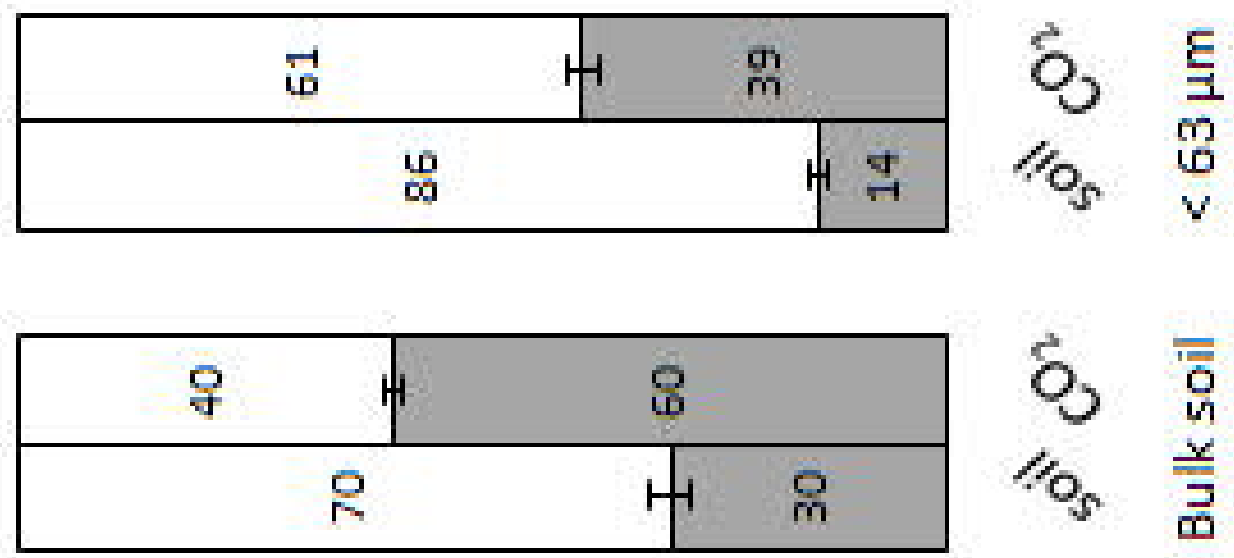

$\frac{8}{8} 8$ 8 8 व
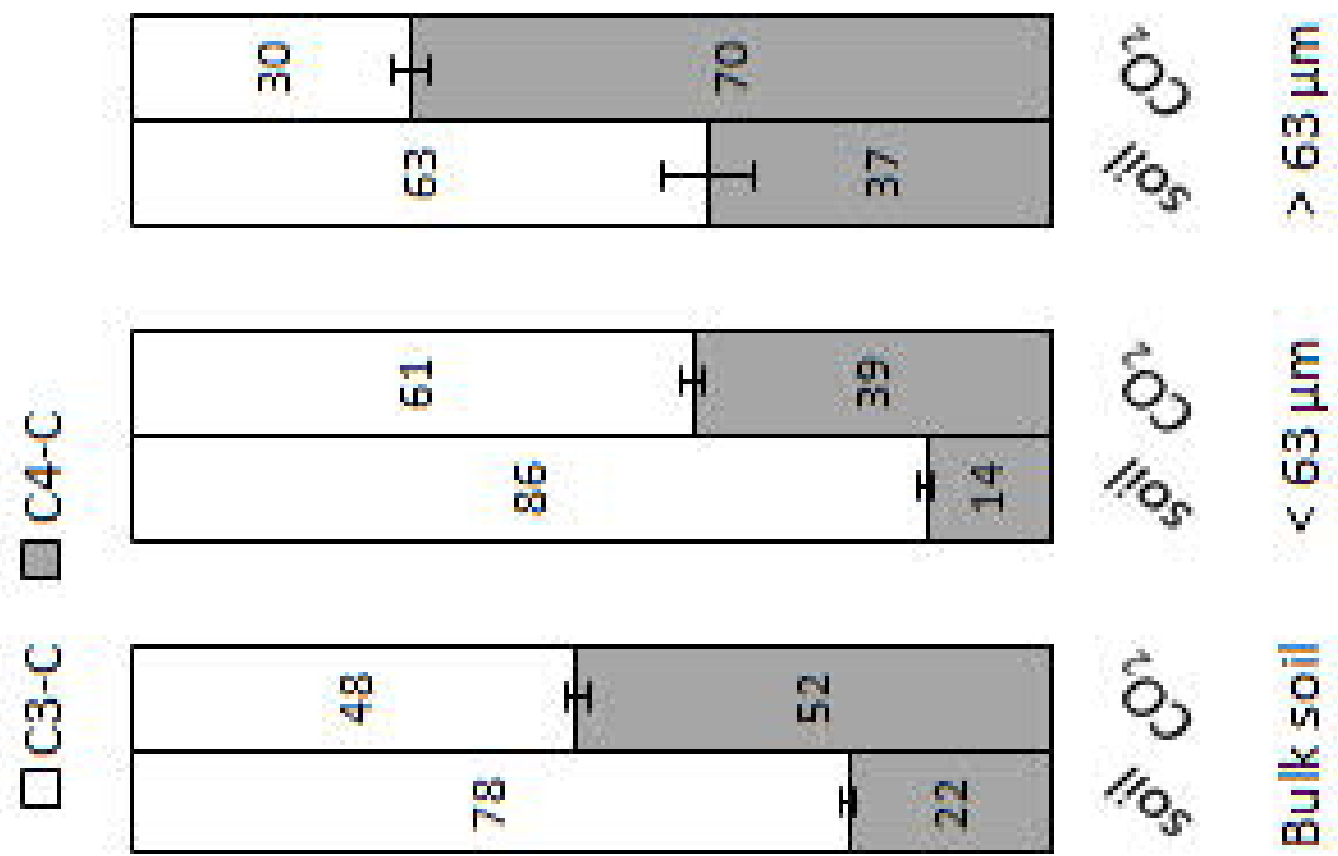

क 8 8 8 8 8 
a) ASKITS

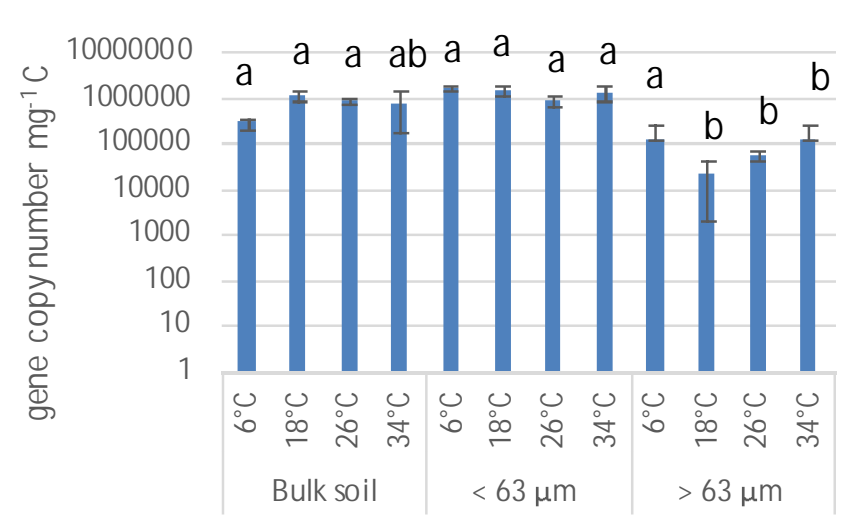

c) ASKB16S

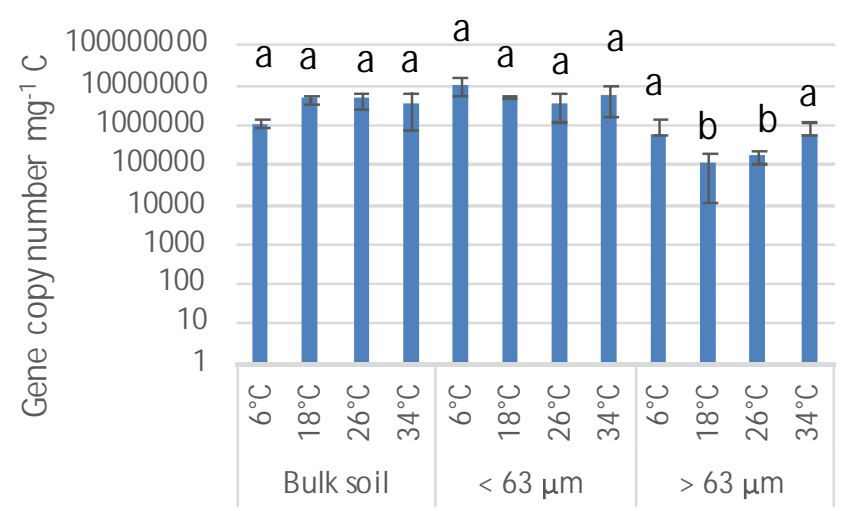

e) ASKA16S

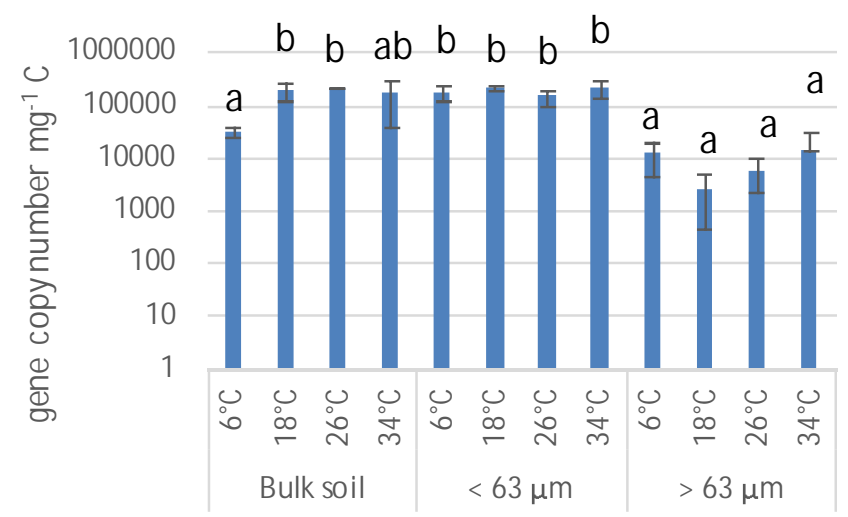

b) LUN ITS $b \quad b \quad b \quad b$

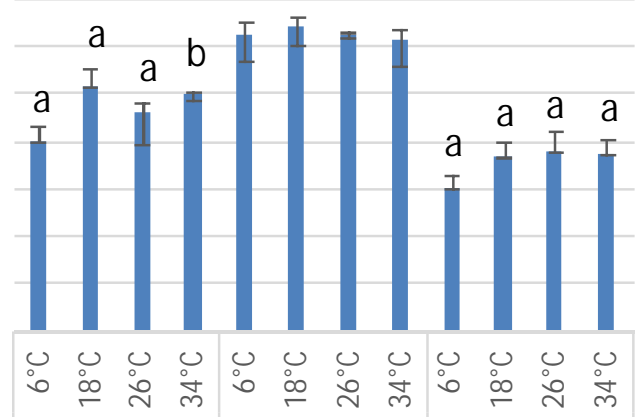
Bulksoil $\quad<63 \mu \mathrm{m} \quad>63 \mu \mathrm{m}$

d) LUN B16S

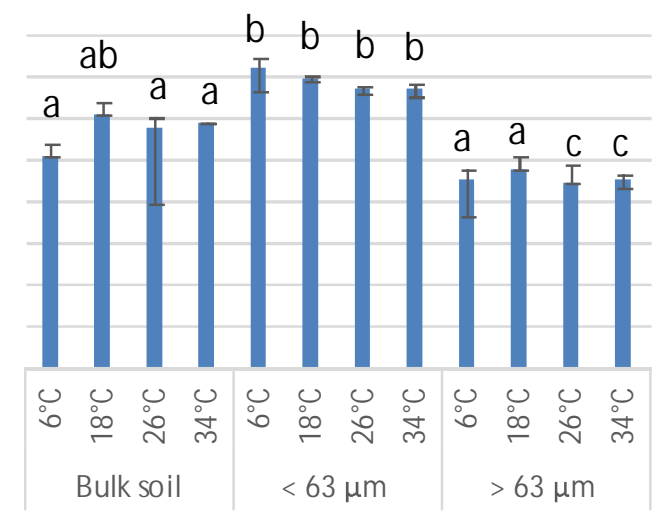

f) LUN A16S

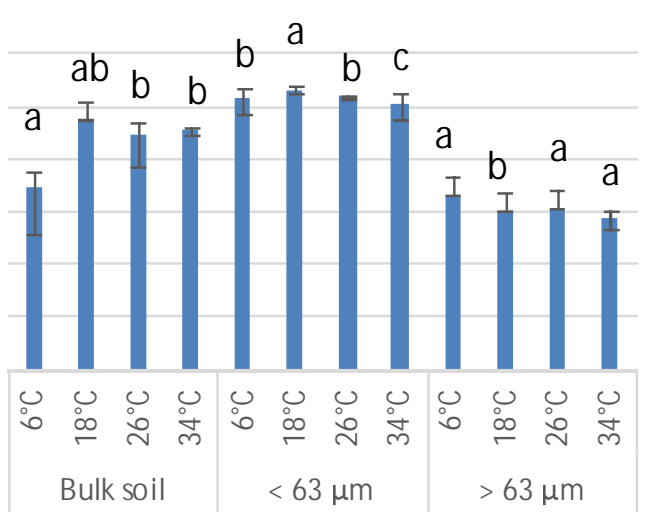


